


\title{
Filosofia do corpo e inventário da dor: (I) elementos para uma fenomenologia da experiência do membrofantasma
}

Autor(es): $\quad$ Umbelino, Luís António

Publicado por: Imprensa da Universidade de Coimbra, Instituto de Estudos Filosóficos

URL

persistente:

URI:http://hdl.handle.net/10316.2/42149

DOI:

DOI:http://dx.doi.org/10.14195/0872-0851_51_5

Accessed : $\quad$ 26-Apr-2023 15:35:07

A navegação consulta e descarregamento dos títulos inseridos nas Bibliotecas Digitais UC Digitalis, UC Pombalina e UC Impactum, pressupõem a aceitação plena e sem reservas dos Termos e Condições de Uso destas Bibliotecas Digitais, disponíveis em https://digitalis.uc.pt/pt-pt/termos.

Conforme exposto nos referidos Termos e Condições de Uso, o descarregamento de títulos de acesso restrito requer uma licença válida de autorização devendo o utilizador aceder ao(s) documento(s) a partir de um endereço de IP da instituição detentora da supramencionada licença.

Ao utilizador é apenas permitido o descarregamento para uso pessoal, pelo que o emprego do(s) título(s) descarregado(s) para outro fim, designadamente comercial, carece de autorização do respetivo autor ou editor da obra.

Na medida em que todas as obras da UC Digitalis se encontram protegidas pelo Código do Direito de Autor e Direitos Conexos e demais legislação aplicável, toda a cópia, parcial ou total, deste documento, nos casos em que é legalmente admitida, deverá conter ou fazer-se acompanhar por este aviso.






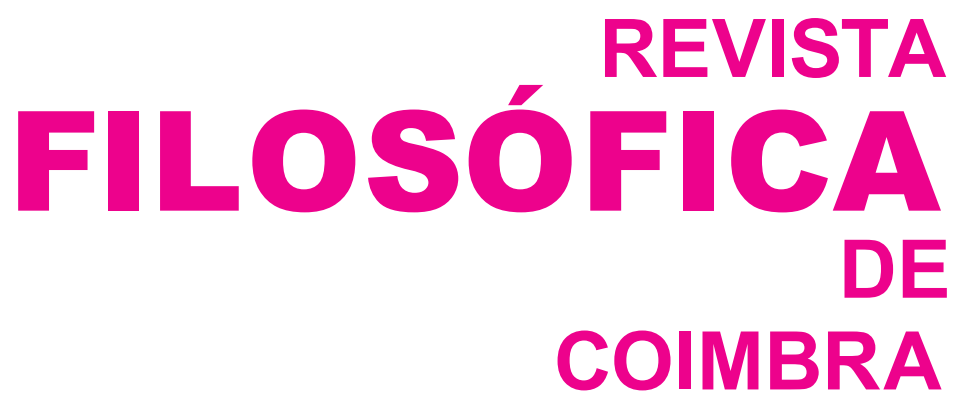

vol. 26 - número 51 - março 2017

vol. 26 - número 51 - março 2017

Fundação Eng. António de Almeida

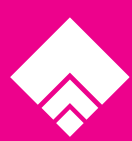




\title{
FILOSOFIA DO CORPO E INVENTÁRIO DA DOR: (I) ELEMENTOS PARA UMA FENOMENOLOGIA DA EXPERIÊNCIA DO MEMBRO-FANTASMA*
}

\author{
PHILOSOPHY OF THE BODY AND THE INVENTORY OF PAIN: \\ (I) ELEMENTS OF A PHENOMENOLOGY OF THE PHANTOM-LIMB \\ EXPERIENCE
}

\section{LUÍS ANTÓNIO UMBELINO**}

Resumo: O presente trabalho pretende medir a atualidade, alcance e implicações filosóficas da análise merleau-pontyana da célebre experiência do membro-fantasma. É nossa intenção sublinhar que também neste caso, que se alinha com o fenómeno das incorporações de "membros protésicos" e com a experiência das localizações selvagens da dor fantasma, se trata de "apreender a humanidade antes de mais como uma outra maneira de ser corpo", um corpo anónimo e mundanizado que se compreende nas sínteses do esquema corporal, nas anexações do hábito e nas "recordações" práticas e motoras sustentadas pelo arco intencional.

Palavras-chave: Membro-fantasma, anonimato, corpo, tempo.

\begin{abstract}
In this paper we aim at measuring the actuality, range and major philosophical implications of merleau-ponty's analysis of the famous experience of the phantom limb. It is our intention to underline that, in this case

Résumé: Dans ce travail, nous voulons mesurer l'actualité, la portée et les implications philosophiques de l'analyse merleau-pontyenne de la célèbre expérience du membre-fantôme. Aussi dans ce cas bizarre,

* O presente texto foi elaborado no contexto do projeto de investigação "Fenomenología del cuerpo y análisis del dolor" (FFI2013-43240-P), financiado pela Dirección General de Investigación Científica y Técnica do Ministerio de Economía y Competitividad de Espanha. Ao coordenador do projeto, Professor Doutor Agustín Serrano de Haro (CSCI - Madrid) deixo aqui o meu agradecimento mais sincero e reconhecido por ter tornado possível, com a sua generosidade, apoio e orientação, o trabalho de investigação cujos resultados aqui se começam a publicar.

** Departamento de Filosofia, Comunicação e Informação; Unidade I\&D CECH; Proyecto I\&D "Fenomenología del cuerpo y análisis del dolor" (FFI2013-43240-P); email: lumbelino@fl.uc.pt
\end{abstract}


- that aligns with the case of prosthesis incorporation and the case of savage localizations of phantom pain - what first is decisive is "to apprehend humanity, first of all as another way of being a body", of being an anonymous munda$n e$ body that we can understand at work in the synthesis of the corporeal scheme, in the annexations of the habit and in the practical and motor remembering made possible by the intentional arch.

Key-words: Phantom-limb; anonymity; body; time. qui peut être rapproché du phénomène d'incorporation des «membres prothétiques» et de l'expérience des localisations sauvages de la douleur fantôme, il s'agit «de saisir l'humanité d'abord comme une autre manière d'être corps», un corps anonyme et mondain qui commence à être compris dans les synthèses du schéma corporel, dans les annexions de l'habitude et dans les «souvenirs» pratiques et motrices enracinés par l'arche intentionnelle.

Mots-clés: Membre-fantôme; anonymat; corps; temps.

\section{Inventário da dor e experiência do amputado (nota introdutória).}

O interesse pela experiência do membro-fantasma é antigo e constante. Ambroise Paré (1510-1590), barbeiro de profissão e mais tarde cirurgião do exército francês, documentou o fenómeno em termos médicos pela primeira vez em meados do séc. XVI ${ }^{1}$. Descartes, no momento das Meditações em que analisa os enganos dos sentidos, refere-se a histórias relatadas de dores fantasma em membros amputados e declara ter ouvido "outrora, de homens a quem foram cortados uma perna ou um braço, que ainda algumas vezes lhes parecia sentirem dores na parte do corpo que faltava"2. Herman Melville também descreveu o fenómeno em Moby Dick, como não poderia deixar de ser, pela voz do estropiado capitão Ahab:

- Vamos então. E como podes saber se uma coisa viva, uma coisa pertencendo a uma criatura pensante não está aí, invisível e reconhecível, no ponto onde estava a minha perna arrancada, no ponto onde te mandei colocá-la? Nos momentos em que estás mais só contigo mesmo nunca tiveste medo das

1 Ambroise Paré, Oeuvres complètes d'Ambroise Paré (t. I, II, III) avec les variantes [...], accompagnées de notes historiques et critiques et précédées d'une introduction sur l'origine et les progrès de la chirurgie en Occident du sixième au seizième siècle et sur la vie et les ouvrages d'Ambroise Paré par J.-F. Malgaigne, Paris, London, 1840-1841. Texto disponível e consultado online em http:/gallica.bnf.fr/ark:/12148/bpt6k65305763/ f44.item.r $=$ sentir, $\% 20$ membre

2 R. Descartes, Meditações sobre a Filosofia Primeira, trad. port. (Coimbra: Almedina, 1988), 205. 
indiscrições de Deus? Pára, velho, não fales! E se sinto a dor da minha perna esmagada, se bem que esteja agora apodrecida há muito, então, carpinteiro, porque não poderás tu sentir os sofrimentos atrozes na eternidade do Inferno mesmo quando o teu corpo estiver apodrecido? Ah! ${ }^{3}$

Ainda na segunda metade do séc. XIX, Silas Weir Mitchell ${ }^{4}$, desconhecendo aparentemente aquelas descrições percursoras, analisou o misterioso membro fantasmagórico sob o conceito de "alucinação sensorial"; ao caso dedicou dois livros de neurologia aos quais acrescentou, posteriormente, um conto anónimo intitulado The Case of George Dedlow. Será, no entanto, o neurologista inglês John Hughlings Jackson quem cunhará o termo "membro-fantasma" em finais do séc. XIX ${ }^{5}$, atestando um interesse científico persistente e, também, uma curiosidade filosófica perene que virá a ser ilustrada, em meados do séc. XX, nomeadamente, pelas análises fenomenológicas de M. Merleau-Ponty ${ }^{6}$.

As análises merleau-pontyanas permanecem hoje incontornáveis. No seu estimulante projeto de "autobiografia fenomenológica"7 da experiência do membro-fantasma, Vivian Sobchack, ela própria amputada de uma das pernas no seguimento de um cancro dos tecidos moles, confirma-o claramente. De facto, é com o recurso ao horizonte fenomenológico e assumindo a inspiração merleau-pontyana que enfrenta a enigmática experiência de olhar para o seu corpo esticado frente a si como um objeto: afirma nada ver ali "onde a minha perna transparentemente ausente estava" e, simultaneamente, confirma experimentar "inequivocamente 'algo' aqui - algo como "a estranha positividade" de certa "presença de uma ausência" ". Será num mesmo sentido que chegará ainda a notar, com acuidade, que derradeiras repercussões da circunstância de experimentar a presença da ausência de uma parte do corpo obrigam a alinhar tal experiência, por um lado, com o fenómeno da in-

${ }^{3}$ Herman Melville, Moby Dick, trad. port., (Lisboa : Relógio d’Água, 2005), 502-503.

4 Cf. S. W. Mitchell, «Phantom limbs», in Lippincott's Magazine of Popular Literature and Science, vol. 8 (1871), 563-569.

5 J. Hughlings Jackson, Selected writings (London: Hodder and Stoughton, 1932), 440.

6 No contexto deste trabalho tomaremos como referência principal as análises de Merleau-Ponty em Phénoménologie de la perception (Paris: Gallimard, 1945), 87-113.

7 Vivian Sobchack, "Living a Phantom Limb: on the Phenomenology of Bodily Integrity", in Body and Society, vol. 16, nº 3 (2010), 52.

8 Sobchack, "Living a Phantom Limb", 57: "'something' sort like my leg, but not exactly coincident with my memory of its subjective weight and length; and the 'here' somewhere in the vicinity my leg had previously occupied, but not exactly coincident with what had been its objective form and boundaries"

9 Sobchack, "Living a Phantom Limb", 58. 
corporação protésica ${ }^{10} \mathrm{e}$, por outro, com a enigmática localização selvagem de uma dor fantasma ${ }^{11}$ situada nos arredores do corpo. Eis as suas palavras:

De facto, inicialmente a maior parte da minha dor tinha mais a ver com as sensações pós-operatórias de uma cirurgia invasiva do que com a presença dissonante do "fantasma". No entanto, ocasionalmente eu sinto de facto dor como um efeito posterior da minha amputação. $\mathrm{O}$ enigma aqui é o seguinte: não sentido já qualquer tipo de "membro-fantasma", não tenho qualquer ideia de "onde" esta dor está localizada (...). O enigma é que não a sinto no meu corpo ou como o meu corpo - e, no entanto, sinto-a (...). Isto é, a minha nova imagem corporal (e talvez o meu novo mapa corporal), de novo completamente integrada "como um todo", não tem lugar para esta dor. Embora "minha", a dor é no entanto completamente alienada para um lugar qualquer "fora" do meu corpo vivido atual, para uma vizinhança genérica do meu lado esquerdo e do meu coto esquerdo que não consigo determinar. Em suma, apesar de a dor estar em lado algum (...), sinto-a sempre "aqui" como estando algures "ali". ${ }^{12}$

Esta dor, sentida aqui sem lugar onde se localizar, sentida agora quando já não deveria estar presente, considera-a V. Sobchack o derradeiro enigma

10 Sobchack, "Living a Phantom Limb", 63.

11 Para uma aproximação ao tema da "dor fantasma" (que não analisaremos neste trabalho expressamente, mas apenas em função do esclarecimento do fenómeno do membro-fantasma), nomeadamente a partir de estudos de caso, veja-se, por exemplo, os seguintes trabalhos: R. Melzack, "Phantom Limbs", in Scientific American, no 266 (1992), 120-126; Annie Woodhouse, "Phantom Limb Sensation", in Classical and Experimental Pharmacology and physiology, 32 (2005), 132-134; Finn Nortvedt, Gunn Engelsrud, "Imprisoned in pain: analysing personal experiences of phantom pain", in Medical Health Care and Philosophy, $\mathrm{n}^{\circ} 17$ (2014), 599-608; C.S. Crawford, "From Pleasure to Pain: the role of the MPQ in language of phantom limb pain", in Social Science \& Medicine, 69(5), 2009, 655-661; C. S., Crawford, "You don't need a body to feel a body: phantom limb syndrome and corporeal transgression", in Sociology of Health \& Illness, 35 (3), 2013, 1-15. V. S. Ramachandram, W. Hirstein, "The Perception of Phantom Limbs. The D. O. Helb Lecture", in Brain, no 121 (1998), 1603- 1630. Ramachandram e Hirstein tipificam deste modo as ocorrências da dor fantasma: "Although phantoms are most commonly reported after amputation of an arm or leg, they have also been reported following amputation of the breast, parts of the face, or, sometimes, even internal viscera, e.g. one can have sensations of bowel movement and flatus after a complete removal of sigmoid colon and rectum, and phantom 'ulcer pains' after gastrectomy. It has also been noted that phantom erections and ejaculation can occur in paraplegics as well as in patients who have had the penis removed, and we have personally seen patients with phantom menstrual cramps after hysterectomy. Or even the acute pain of appendicitis following removal of the inflamed appendix". V. S. Ramachandram, W. Hirstein, "The Perception of Phantom Limbs", 1605.

12 Sobchack, "Living a Phantom Limb", 64-65. 
da sua experiência de amputada. Por essa razão entende ser significativo que não sentindo já qualquer tipo de "membro-fantasma", um derradeiro traço de tal experiência a confronte com a bizarra situação de sentir uma dor $e$ não perceber "onde" tal dor está localizada. De algum modo tal dor parece ter sido alienada para os arredores do corpo, por vezes, como afirma a autora, para uma “vaga faixa de espaço 'não preenchido', para uma terra de ninguém separando duas perceções diferentes do meu corpo que não podem confundir-se." 13 No entanto, que a dor não tenha já lugar no "corpo vivido atual", não significa que não continue a "encontrar-se", a "localizar-se aqui no corpo - mas num corpo que, então, sob o corpo atual, se revela uma vocação de dispersão, de alienação, de expansão. Esse corpo subterrâneo não se mantém completo nos seus próprios limites materiais, mas na correspondência dinâmica às interpelações práticas do mundo. Por meio desse dinamismo aparenta ser capaz de segurar o tempo e o espaço de uma dor que, em rigor, deveria ter desaparecido juntamente com a parte do corpo amputada e não mais deveria ter voltado - muito menos para os arredores de um corpo de novo preenchido por uma renovada imagem corporal. Na verdade, tal dor é ainda e sempre do corpo: ainda e sempre experiência concomitante do corpo anónimo, desse corpo capaz de todas as fantasmagorias e que ora se faz propriamente corporal, ora se dirige por refração à existência pessoal ${ }^{14}$.

Neste sentido, dir-se-ia que o "espaço infestado de dor" 15 , de que fala Merleau-Ponty a propósito da dor física, exige ser compreendido para além da localização expressa e pontual de sensações sobre um corpo físico expressamente cartografado; tal "espaço" da dor dirá respeito à totalidade de um corpo que se completa espacialmente e perdura temporalmente - por força de uma vocação de incorporação, anexação, virtualização ou alienação interminável - na unidade (ausente) sempre procurada do mundo, ou melhor, na promessa mundanizada do que pode completar o sistema do corpo. Será nestas circunstâncias que a experiência do membro-fantasma se alinhará com o caso da incorporação de membros protésicos e se poderá compor igualmente com o derradeiro enigma de uma dor vivida aqui mas "localizada" por aí. Sobre aquela experiência testemunhará o amputado as capacidades inusitadas de incorporação de um corpo que persiste uma totalidade vivida; sobre esta dor propriamente física confirmará que se pode separar da sua fonte e não coincidir com a respeita origem (quer no tempo, quer num lugar objetivo). Nesta circunstância, de facto, constata-se que a dor do corpo que me

13 Sobchack, "Living a Phantom Limb", 57.

14 Merleau-Ponty, Phénoménologie, 104 : "L'homme concrètement pris n'est pas un psychisme joint à un organisme, mais ce va-et-vient de l'existence qui tantôt se laisse être corporelle et tantôt se porte aux actes personnels. "

15 Merleau-Ponty, Phénoménologie de la perception, Paris, Grallimard, 1945, 110. 
dói ${ }^{16}$ não é, em rigor, concebível como uma propriedade (de uma lesão, por exemplo) mas como um evento: um evento que pertence, justamente, à natureza essencialmente dinâmica e processual de um corpo cujo modo de ser é o de um devir persistente de mundo.

Num certo sentido, é justamente por obrigar a rever as nossas conceções habituais sobre o corpo e a corporeidade (e, com elas, as nossas conceções de espaço e de tempo) que o fenómeno do membro-fantasma, nas suas múltiplas repercussões, permanece, de um ponto de vista filosófico, tão insólito quanto significativo. É o que Merleau-Ponty compreendeu bem, tendo sido capaz de traçar sobre tal experiência um mapa de análise que permanece incontornável.

De tal mapa faz parte, como primeira referência orientadora, o reconhecimento (que leva a sério o que reconhece) de que algo como um "membro-fantasma" não seria concebível antes ou independentemente de alguém o experienciar como tal. Mais precisamente, tal enigmático fenómeno a nada corresponderia se não fizesse parte da experiência corporalizada de estar-no-mundo a possibilidade de viver (de sintetizar, de significar pré-reflexivamente através de uma consciência incarnada) como ainda presente um membro objetivamente ausente ${ }^{17}$. Estas considerações, enquanto propriamente fenomenológicas, assumem e pressupõem a necessidade de descrever a experiência aqui em questão como já sempre significativa e, portanto, como irredutível ou não equivalente aos respetivos efeitos experimentalmente observáveis, tais como uma abordagem estritamente objetiva os poderia entender. Dito de outro modo, permanece válido para o fenómeno do membro-fantasma o que $\mathrm{S}$. Kay Toombs, doente de esclerose múltipla, afirmou em The Meaning of Health:

16 Agustín Serrano de Haro, “Atención y Dolor. Análisis Fenomenológico”, in AAVV, Cuerpo Vivido, (Madrid: Encuentro, 2010), 123-161.

17 De facto, fora ou independentemente da experiência primitiva de uma aparentemente bizarra corporeidade vivida algo como um "membro-fantasma não poderia começar a ser estudado cientificamente, já que sobre um corpo orgânico amputado não se poderia nunca descobrir e investigar um fantasma. Nesta medida, para a análise científica e para a descrição fenomenológica o "membro-fantasma" significará algo de qualitativamente diferente. Dito de outro modo, não se pode confundir ou ignorar o que separa epistemologicamente tudo aquilo que de tal fenómeno se oferece ao ponto de vista "exterior" da análise médica, anatómica ou neurofisiológica e o que desse fenómeno permanece demonstrativo da anterioridade e irredutibilidade de uma perspetiva vivida sobre o corpo e a corporeidade. $\mathrm{O}$ mesmo se deverá argumentar em relação à consideração da dor física que, no contexto de tal experiência do membro-fantasma, se desvenda de modos inesperados e insólitos. Importa levá-los a sério e assumir que em tal experiência do membro-fantasma algo de decisivo sobre a dor se desvenda nos planos arcaicos da corporeidade complexa de alguém. 
Embora como doente de esclerose múltipla possa reconhecer a dormência de um dos meus braços como "esclerose múltipla", e também como envolvendo certos transtornos de certos circuitos sensoriais, eu não experiencio diretamente a lesão do sistema nervoso central que é a doença declarada conhecida pelo médico. ${ }^{18}$

A abordagem fenomenológica implica - assim se esboçando um segundo eixo orientador - que, também em relação ao fenómeno do membro-fantasma, se descartem as explicações estritamente fisiológicas, mas também as explicações psicológicas e as explicações mistas psico-fisiológicas. Merleau-Ponty, coerente com o seu programa filosófico, entende aquelas abordagens como formas funestas de cedência inconsequente a preconceitos objetivistas e a pontos de vista típicos de um pensamento causal: por igual ignoram que na passagem do psíquico ao orgânico se anuncia um problema que não se resolve naquelas opções tendencialmente aporéticas, antes reclamando uma investigação mais arqueológica do respetivo sentido. Não quer isto dizer, no entanto, que a experiência do membro-fantasma se explique através de uma entidade mais ou menos fantasiosa e extra-psicológica ou extra-fisiológica. Tal fenómeno está, obviamente, "relacionado às duas séries de condições"19 psicológicas e fisiológicas; mas - e este é um aspeto decisivo -, de acordo com Merleau-Ponty, para se entender de que modo tais condições intervêm no fenómeno é necessário procurar um plano mais arcaico de análise, um plano a partir do qual se torne realmente compreensível como tais condições são, em conjunto, mobilizadas no centro da experiência vivida da presença de um membro ausente. De facto,

o membro fantasma não é o simples efeito de uma causalidade objetiva, nem de uma cogitatio. Ele só poderia ser uma mistura dos dois se encontrássemos o meio de articular um sobre o outro o "psíquico" e o "fisiológico", o "para si" e o "em si" e de arranjar entre eles um encontro, se os processos em terceira pessoa e os atos pessoais pudessem ser integrados num meio que lhe fosse comum. ${ }^{20}$

18 S. Kay Toombs, The Meaning of Illness. A Phenomenological Account of the Different Perspectives of Physician and Patient (Springer Science, Business Media, B.V., 1992), 77.

19 Merleau-Ponty, Phénoménologie, 95. Para Merleau-Ponty, não se trata de ignorar ou negar as contribuições neurocientíficas, médicas, ou da psicologia cognitiva para o estudo do membro-fantasma. Outrossim, argumenta-se que entre a investigação segunda das causas e processos das sensações do membro-fantasma, desenvolvidas pelo ponto de vista objetivante da abordagem científica, e a descrição do primitivamente experienciado sob o mesmo nome do ponto de vista da experiência incarnada ou do corpo vivido não há forçosamente paralelo ou verdadeira analogia.

20 Merleau-Ponty, Phénoménologie, 92. 
Haverá, portanto, que denunciar com clareza a superficialidade das abordagens que ignoram tal "meio" integrador e organizador do psíquico e do orgânico. Assim, por exemplo, no caso do membro-fantasma, haverá ainda e sempre que tentar perceber como a atitude global da nossa inerência incarnada ao mundo chega a precisar, para se concretizar, das condições psico-físicas específicas de um sistema muscular, de um sistema nervoso central ou de um circuito sensório-motor; ou como, ao mesmo tempo, tais condições "materiais" só ganham sentido - e, portanto, se fundam - sobre o pano de fundo arcaico do ser-no-mundo habitual ${ }^{21}$ (que, por seu turno, se "mede" reversivelmente por aqueles circuitos).

Seguindo tal via de investigação, encontraremos um terceiro eixo orientador da análise ao vislumbrar a tensão que, no coração da experiência do amputado, se joga constantemente entre o "saber" insólito de tal modo de ser-no-mundo habitual e o saber expresso do corpo atual. A questão será aqui a de compreender como o "corpo habitual pode aparecer como fiador do corpo atual" 22 , única forma de avistar os derradeiros marcos orientadores da presente investigação, a saber: o modo como o caso do membro-fantasma obriga a conceber "um meio-termo entre a presença e a ausência" 23 e o modo como compele a subverter, não apenas a distinção entre o "real" e o "fantasma", mas também a costumeira prevalência do primeiro sobre o segundo.

\section{Sínteses, incorporações, anexações e reencenações práticas.}

O problema do membro-fantasma formula-se de modo simples: trata-se de saber como se faz a experiência, no presente e como real, de uma "parte" do corpo ${ }^{24}$ fisicamente ausente.

Pode responder-se a este problema supondo que se trata de um mero equívoco, o de acreditar ilusoriamente que o membro ainda existe mesmo quando se comprova objetivamente que já lá não está. Tal explicação, no entanto, permanece inconsistente por força de uma evidência simples: ninguém faz a experiência do membro-fantasma porque a decida ou deseje fazer expressamente; ou seja, a experiência do membro-fantasma não é da ordem

21 Merleau-Ponty, Phénoménologie, 103: “C'est une vérité interne pour l'existence la plus intégrée de se donner un corps habituel.»

22 Merleau-Ponty, Phénoménologie, 98. (Partilhamos, neste ponto, a opção de tradução de C. Moura na edição portuguesa da editora Martins Fontes, São Paulo, 2006, 123).

23 Maurice Merleau-Ponty, Phénoménologie, 96.

24 Sobchack, "Living a Phantom Limb", 57: "Which brings us (...) back to the (...) question (...): where was my leg?" 
do "eu penso que ..." 25 , não podendo explicar-se superficialmente por meio de uma qualquer nostalgia "psicológica" voluntária que representaria a presença efetiva do "antigo" membro amputado cuja perda "não se aceita".

Poderia, então, supor-se legítima uma resposta contrária e uma segunda forma de explicação: o membro-fantasma seria o simples efeito de processos mecânicos "cegos" 26 apenas acessíveis a uma cartografia fisiológica na "terceira pessoa". Todavia, também nesta abordagem subsiste um equívoco: ao posicionar-se a análise a um tal nível da explicação causal, trabalha-se com uma conceção de corpo forçosamente reduzido à objetividade de "partes" atomizadas, assim se ignorando a respetiva dimensão vivida - dimensão essa que, justamente, nos revela que os "processos do corpo" nunca são cegos ou puramente mecânicos, mas antes, isso sim, desde sempre significativamente polarizados por uma qualquer "direção da situação"27. Dito de outro modo, o amputado não é nunca, realmente, o joguete de uma causalidade objetiva escondida nos processos orgânico.

Finalmente, também não se poderá aceitar a solução de um psiquismo desencarnado que "imaginaria" um membro para substituir automaticamente o membro amputado. Tal posição é apenas uma variação das respostas anteriores e, por isso, mais não faz do que incluir cumulativamente os seus equívocos; uma vez mais, portanto, não se dilucida o fundo de vivido fora do qual, na verdade, tal enigmático fenómeno permanece inconcebível.

O pano de fundo desta crítica plurívoca representa, simultaneamente, a indicação de uma direção precisa da investigação que aponta para a necessidade de considerar a experiência do membro-fantasma a partir de um plano arqueológico de análise. De facto, será que poderíamos representar psicologicamente o membro amputado se a materialidade do corpo não mantivesse aberta a ligação ao mundo das ações habituais? Por outro lado, será que a materialidade do corpo poderia continuar aberta a tal mundo prático se não fosse desde sempre uma potência de significação da prosa do mundo e não apenas um conjunto de processos ou reflexos cegos? O que está verdadeiramente em questão na experiência do membro-fantasma é, para Merleau-Ponty, algo de mais complexo: tal experiência demonstra e revela de modo paradigmático em que medida, se concretamente considerados, não somos um psiquismo unido a um organismo "mas este vai-e-vem da existência que

25 Merleau-Ponty, Phénoménologie, 96.

26 Merleau-Ponty, Phénoménologie, 94.

27 Merleau-Ponty, Phénoménologie, 94: «En réalité les réflexes eux-mêmes ne sont jamais des processus aveugles : ils s'ajustent à un 'sens' de la situation, ils expriment notre orientation vers un 'milieu de comportement' tout autant que l'action du 'milieu géographique' sur nous.» 
ora se deixa ser corporal, ora se dirige aos atos pessoais ${ }^{28}$. Para compreender tal vai-e-vem, segundo Merleau-Ponty, apenas a "perspetiva do ser no mundo" 29 se revelará adequada, ao desvendar um modo de pertença ou inerência incarnada que se deve reconhecer originária. Também no caso específico do membro-fantasma se tratará, portanto, de "apreender a humanidade antes de mais como uma outra maneira de ser corpo" ${ }^{30}$ : de ser um corpo que se definirá essencialmente como "veículo do estar no mundo"31, ou seja, como vocação de comprometimento contínuo e persistente com "certos projetos" num meio definido.

Como é sabido, uma tal investigação do corpo assume lugar central nas análises fenomenológicas merleau-pontyanas do entrelaçamento entre o "sujeito" ativo que percebe (entendido como consciência incarnada) e o mundo que está para ser percebido. Neste contexto, a originalidade de Merleau-Ponty será a de reconhecer que o corpo próprio, enquanto essencialmente distinto do corpo objetivo, não significa apenas o corpo que sinto meu, nem apenas o espaço subjetivo de sensações corporais, mas também e fundamentalmente a "minha" experiência pré-reflexiva global de ser no mundo, enquanto tal experiência vivida é propriamente corporalizada e caracterizada por um silencioso comprometimento motor no mundo. A forma de tal comprometimento corresponde, arqueologicamente, a um modo de co-respondência dinâmica e orientada a um meio de comportamento ou a uma direção interpelante da situação. Tal orientação, polarizada por exigências práticas, é dita "silenciosa" na medida em que tal corpo apropriado ao "meu" modo de ser-no-mundo é "percebido", originariamente, como "vivido"; ou seja, o corpo não é "percebido" tematicamente, mas como exercício silencioso, anónimo, pré-pessoal e pré-reflexivo de uma essencial vocação de mundo. O mesmo é dizer que ser corpo significa, antes de mais, agir, significar e existir em algum lado sem precisar de refletir e conceber expressamente um corpo mais ou menos definido como "meu". O corpo de que aqui se trata não é, portanto, concebível como um objeto feito de "partes" ou "peças" justapostas e de algum modo ligadas a "mim"; trata-se antes de um "meio" silencioso (o seu modo de aparecer não é, justamente, o da interposição entre sujeito e mundo, mas o do vínculo refratário que me dá mundo) de ser no mundo e de ter um mundo. O ponto é importante:

28 Merleau-Ponty, Phénoménologie, 104.

29 Merleau-Ponty, Phénoménologie, 97.

30 M. Merleau-Ponty, La Nature. Notes de cours du Collège de France (Paris : Seuil, 1994), 269.

31 Merleau-Ponty, Phénoménologie, 97. 
eu observo os objetos externos com o meu corpo, manuseio-os, inspeciono-os, rodeio-os, mas quanto ao meu corpo eu não o observo; seria necessário, para o fazer, dispor de um segundo corpo que não seria ele próprio observável (...). Enquanto ele vê ou toca o mundo, o meu corpo não pode, pois, ser visto nem tocado. E o que o impede de ser alguma vez um objeto, de jamais ser 'completamente constituído', é o facto de o corpo ser aquilo pelo qual há objetos ${ }^{32}$.

Um tal corpo que não deixo de ser é uma potência dinâmica de pertença aos arredores mundanos e, nessa medida, é de molde a tornar impensável a ausência ou variação da sua presença. Nunca se interpondo entre "mim" e as "coisas", tal corpo é vivido e não concebido expressamente; ou seja, o seu modo de presença não é explícito (nem, em rigor, explicitável), antes correspondendo a uma forma de apagamento tácito que "me" coloca já sempre percetivamente no mundo, enraizado nas coisas e entendendo-me a seu respeito. Há, portanto, um modo de ser do corpo (essa presença silenciosa e integralmente apropriada ao ser-no-mundo) que o mantém - se quiséssemos utilizar o vocabulário das análises percursoras de Maine de Biran - inintencionado. De facto, enquanto "veículo do ser-no-mundo" o corpo é originariamente exercido, mas não percebido como objeto intencional. De algum modo, permanece como que fenomenologicamente escondido no seu perseverar dinâmico, desse modo permitindo visar imediatamente as tarefas e comportamentos a realizar. Dir-se-ia que o corpo, enquanto vivido, se "percebe" apenas a experienciar, a percecionar, a pertencer por conivência (e nisto será essencialmente distinto dos restantes objetos do mundo), e não como algo estritamente experienciado ou a experienciar, nunca como algo concebido ou a conceber expressamente.

De acordo com Merleau-Ponty, tal dinamismo do corpo, embora permanece anónimo ou pré-pessoal, não deixa de ser uma forma de expressar e significar o mundo. Não, certamente, de forma temática mas sim de forma prática. Ou seja, ao nível da corporeidade vivida o mundo não é nunca "percebido" como uma soma de estímulos desordenados, do mesmo modo que o dinamismo ou motricidade do corpo nunca é um conjunto de respostas caóticas a estímulos mais ou menos aleatórios; na verdade, por força de uma estranha e irrefletida sincronização familiar, acontece estabelecer-se entre o dinamismo esquemático do corpo e o dinamismo interpelante do mundo uma espécie de "pacto", pelo qual a arquitetura do corpo se completa num arquitetar do mundo e a arquitetura do mundo se completa no arquitetar prático (esquemático e sintetizador) do corpo.

32 Merleau-Ponty, Phénoménologie, 107-108. 
Merleau-Ponty demostra-o, por exemplo, ao considerar o caso da perceção sensorial. Entende que não se trata de um mecanismo exclusivo de receção de estímulos exteriores, nem de um processo psico-neurológico de organização, mas antes o resultado de uma situação na qual uma interpelação dinâmica solicita à unidade global do corpo determinados gestos, ou melhor, certas respostas (propriamente afetivas) de envolvimento e de investimento sintetizador a tarefas existentes ou possíveis. Nesta medida, deve concluir-se que o modo essencial de ser corporalmente no mundo se traduz, originariamente, por uma forma de conivência prática que é, de direito, uma praktognosia ${ }^{33}$. Quer isto dizer que o comprometimento dinâmico do corpo inaugura uma ordem de coexistência com as coisas do mundo que as "entende"; não, diga-se uma vez mais, como entidades representáveis, mas como "polos de ação" aos quais a correspondência da motricidade corporal, justamente, sabe devolver dinamicamente um sentido práxico. Essas correspondências serão sempre, portanto, significativas e o corpo vivido ou fenomenal sempre igualmente expressivo.

Nesta medida, poderá dizer-se que o corpo é um "nó de significações vivas" traçadas pré-pessoalmente e em tudo semelhante a uma "obra de arte" 34 ; deve, no entanto, notar-se que tal caracterização só faz realmente sentido se se acrescentar que o corpo é um tal "nó" significante por força dos poderes anónimos da sua motricidade constitutiva, do seu "saber" prático de enraizamento desde sempre mundanizado. De facto, uma tal "experiência" significante "de mundo" enraíza-se na motricidade que faz do corpo sempre "corpo de alguma coisa". Não se trata aqui de propor um jogo de palavras evocador da célebre noção de consciência intencional; se no movimento do corpo vivido se visam as coisas do mundo (ou seja, se um sujeito incarnado as "conhece" por pertença prática), isso significa que o corpo esboça (anonimamente) uma forma de intencionalidade independente de qualquer representação; e esta deve reconhecer-se não apenas como original, mas também como originária ${ }^{35}$. Para distinguir da intencionalidade representacional esta intencionalidade enraizada no modo como a motricidade corporal corresponde anonimamente às interpelações da situação, Merleau-Ponty recorre ao conceito de "intencionalidade motora" 36; e com tal noção sustentará que o

33 Merleau-Ponty, Phénoménologie, 164: “L’expérience motrice de notre corps n'est pas un cas particulier de connaissance; elle nous fournit une manière d'accéder au monde et à l'objet, une 'praktognosie' qui doit être reconnue comme originale et peut-être comme originaire.»

34 Merleau-Ponty, Phénoménologie, 294.

35 Merleau-Ponty, Phénoménologie, 160 : «Ces éclaircissements nous permettent enfin de comprendre sans équivoque la motricité comme intentionnalité originale.»

36 Merleau-Ponty, Phénoménologie, 128 
corpo permanece "um outro sujeito por debaixo de mim", um "sujeito" para o qual "há um mundo antes de eu lá estar e que marca nele o meu lugar."37 Esse corpo é certamente "meu"; mas não é o corpo atual, não é "o corpo momentâneo que permanece o instrumento das minhas escolhas pessoais e se fixa sobre tal ou tal mundo" 38 . Os seus "poderes" são aqueles que derivam de um saber antigo de mundo que se sedimenta pelo hábito e se exerce no conjunto de recursos práticos de pertença ao mundo, recursos sempre disponíveis porque reencenados de forma motora a partir do "esquema corporal" 39 . Merleau-Ponty fala-nos aqui de um corpo habitual que não é senão o "sistema de 'funções' anónimas que envolvem qualquer fixação particular num projeto geral" 40 e, para o caracterizar, liga precisamente as noções centrais de "hábito" e de "esquema corporal".

Se bem entendido ${ }^{41}$ - como imbricamento e movimento de envolvimento e implicação sensório-motor, intersensorial e intrasenorial ${ }^{42}$ - o conceito de "esquema corporal" permite pensar o corpo como "unidade" pré-lógica e pré-temática de implicação e investimento, unidade esta que corresponde à reelaboração constante de um modelo interno ou fundo permanente $\mathrm{e}$ ativo $^{43}$ que permanece estruturalmente aberto a um número indefinido de posições equivalentes e dirigidas a fins presentes ou eventuais ${ }^{44}$. $\mathrm{O}$ "meu" veículo do estar no mundo é, assim, uma espécie de permanência (dinâmica) absoluta, uma sorte de fundo ou campo de presença primordial que contribui para a permanência relativa e sempre em eclipse dos objetos do mundo. É neste sentido que o corpo deve, finalmente, ser entendido como um "hábito primordial" 45 , um "horizonte latente" 46 (anterior a todo o pensamento determinante e persistente na sua vocação praktognósica) da experiência

37 Merleau-Ponty, Phénoménologie, 294.

38 Merleau-Ponty, Phénoménologie, 294.

39 Merleau-Ponty, Phénoménologie, 115 ss.

40 Merleau-Ponty, Phénoménologie, 294.

41 Para uma breve história do conceito e modo de apropriação original de Merleau-Ponty, veja-se Emmanuel Saint Aubert, "Espace et schéma corporel dans la philosophie de la chair de Merleau-Ponty», in A. Berthoz, B. Andrieu (dir.) Le corps en acte, (Presses Universitaires de Nancy, 2010), 122-152.

42 Saint Aubert, "Espace et schéma corporel", 126-127.

43 Saint Aubert, "Espace et schéma corporel", 128.

44 Dorothée Legrand, "The bodily self: The sensori-motor roots of pre-reflective selfconsciousness", in Phenomenology and the Cognitive Sciences, $n^{\circ} 5$ (2006), 97. Veja-se ainda, embora sem partilharmos todas as conclusões da respetiva análise, Shaun Gallagher, "Body schema and intentionality", in J. L. Bermudez, A. Marcel and N. Eilan (eds), The Body and the Self, (Cambridge, The MIT Press, 1995), 225-244.

45 Merleau-Ponty, Phénoménologie, 107.

46 Merleau-Ponty, Phénoménologie, 109. 
de mundo. Acrescente-se um elemento decisivo: tal modo de ser habitual do corpo, no seu dinamismo próprio, é uma forma constante de alienação ou virtualização que se concretiza num gesto de expansão (subversivo das fronteiras materiais do corpo) que anexa as coisas do mundo ou as incorpora por habituação (que não é senão uma forma de habitação).

O fundo da experiência pessoal é, portanto, paradoxalmente pré-pessoal e estrutura-se arqueologicamente através de processos corporais de dilatação espacial, incorporação práxica e anexação dinâmica dos lugares e objetos do mundo. O hábito, tal como Merleau-Ponty o entende, resume tais processos. Considere-se um exemplo prosaico para esclarecer o que aqui está em questão: conduzir um automóvel através de um caminho estreito entre duas outras viaturas estacionadas. É comum em tal circunstância, e sem hesitar ("sem pensar"), o condutor "saber que passa", "saber que cabe" e avançar; o curioso é que, por vezes, se encolhe dentro do carro ao transitar entre os obstáculos. Acontece neste exemplo que o automóvel, objeto exterior para o corpo atual, deixou de ser para o corpo habitual esse objeto cuja grandeza ou volume se determinaria "por comparação com outros objetos"; onde um certo modo de ser corpo separa do automóvel, outro mais antigo, ao contrário, prolonga-se e expande-se ao ponto de transformar o automóvel numa potência voluminosa, na exigência de um certo espaço livre ${ }^{47}$. Dir-se-ia que há um modo de ser corpo que "nos" instala continuamente no automóvel e o faz "participar na voluminosidade do próprio corpo" 48 .

É assim que o corpo habitual oferece ao condutor do automóvel a segurança acrescida de poder desposar as distâncias entre obstáculos; parafraseando outros exemplos merleau-pontyanos, diríamos que é de um mesmo modo que que o corpo habitual instala o músico no seu instrumento musical como em casa, que ao invisual oferece a possibilidade de estender o tato até à ponta da bengala que o orienta, que ao amputado oferta a possibilidade de incorporar uma prótese e, assim, dar vida ao metal ou à madeira. Algo mais se poderia ainda acrescentar: será essa mesma vocação de mundo que - eis o que pretendemos argumentar-, após uma amputação, pode "recusar" a perda de um membro e persistir em manter intacta, ainda que com um membro-fantasma ${ }^{49}$ (mesmo contra a evidência de membro objetivamente ausente) a ponte para o mundo prático.

47 Merleau-Ponty, Phénoménologie, 167.

48 Merleau-Ponty, Phénoménologie, 167.

49 Poderia ainda acrescentar-se, obviamente, e recuperando o tema da dor, mais uma interrogação: como não supor que esse mesmo corpo, ao contribuir para "renovar o esquema corporal" (Merleau-Ponty, Phénoménologie, 166), acompanha as reelaborações da imagem corporal e segura as localizações selvagens de múltiplas sensações dolorosas? 
Merleau-Ponty parece-nos autorizar esta hipótese - V. Sobchack também o notou ${ }^{50}$ - quando, ao referir-se ao caso do membro-fantasma, parece estar por vezes a falar igualmente de membros protésicos. Recorde-se, por exemplo, o momento em que se refere ao impulso prático do ser-no-mundo para dizer que se trata de uma "situação em aberto (...) que permite aos membros serem substituidos" 51 e manterem um igual valor em face das exigências de uma qualquer tarefa motora. A direção da análise merleau-pontyana do membro-fantasma toma, portanto, o caminho - não cartesiano ${ }^{52}$ - indicado pelas possibilidades desta estranha vocação persistente de anexação e incorporação do mundo exercida, por debaixo do corpo momentâneo que me fixa em tal ou tal mundo, pelo corpo habitual. Importa sublinhar o que assim se afirma: a experiência aparentemente bizarra do membro-fantasma não existiria se a experiência pessoal se forjasse apenas em e através do corpo atual (com as suas vicissitudes instantâneas, singulares e plenamente explicitáveis), se tal experiência não fundasse raízes também, justamente, num corpo habitual e na sua vocação anónima e persistente de mundo, que se exerce independentemente do que possamos expressamente pensar ou querer.

\section{Corporeidade fantasmagórica.}

Merleau-Ponty parece-nos claro a respeito do modo como orienta a sua análise: é sob um "um aspeto de generalidade e como ser impessoal" ${ }^{53}$ que, de acordo com o filósofo, o essencial da experiência do membro-fantasma se pode desvendar. Mais precisamente, tal experiência parece esboçar-se a partir de um "híbrido" 54 pré-pessoal entre o "psicológico" e o "fisiológico" 55

50 Sobchack, "Living a Phantom Limb", 63.

51 Merleau-Ponty, Phénoménologie, 93.

52 Merleau-Ponty, Phénoménologie, 95: «C'est parce qu'il est une vue préobjective que l'être au monde peut se distinguer de tout processus en troisième personne, de toute la modalité de la res extensa, comme de toute cogitatio, de toute connaissance en première personne - et qu'il pourra réaliser la jonction du 'psychique' et du 'physiologique'.»

53 Merleau-Ponty, Phénoménologie, 98.

54 Dylan Trigg, The Memory of Place. Phenomenology of the Uncanny, Athens, Ohio, Ohio University Press, 2012, p. 15

55 Sobchack, "Living a Phantom Limb", 53. No caso do 'membro-fantasma' o conhecimento do corpo vivido emerge provisoriamente como a correlação e a síntese da experiência de aspetos subjetivos e objetivos, como a "união dos dois". Não é dizer pouco. De facto, as implicações do que fica dito são várias e, por igual, decisivas: primeiro, há que reconhecer que o vivido, no seu fundo de anononimato silencioso, não exclui as repercussões selvagens de um corpo que se pode fazer presente sem representação no simples apagamento do apagamento do corpo fenomenal (a des-aparição de que fala 
e fundar-se numa tensão ou desacerto que, no coração de uma corporeidade complexa, se revela entre a experiência expressa do corpo atual e a vivência anónima do corpo habitual. No caso específico do membro-fantasma, de facto, tudo indica ser decisiva a polémica entre a evidência expressa de não possuir já uma "parte" do corpo (bem como o acesso ao mundo que lhe correspondia) e a certeza vivida de, "independentemente dos nossos pensamentos voluntários" $" 56$, continuar a manter no presente, por força do dinamismo motor do corpo habitual, a mesma "consistência do nosso mundo" 57 .

O que aqui se torna decisivo é, portanto, a aparente capacidade do corpo para "recordar" ou "reencenar" de modo motor, sempre que necessário, a justa correspondência dinâmica às interpelações do mundo prático, mesmo quando o corpo atual sofreu alterações traumáticas. Dito de outro modo, o corpo é capaz de manter no presente recursos práticos sedimentados, recursos antigos mas nunca verdadeiramente perdidos. Tudo se passa aqui como se, precisamente, o corpo não esquecesse nunca o reportório - anonimamente aprendido num passado vivido e, por isso, conjugando uma memória do corpo - das trocas com o mundo e o mantivesse presente para novas efetuações de incorporação, anexação ou habituação práxica. Este aspeto é importante: entendido a partir da intencionalidade motora, o corpo é um modo de persistência dinâmica que assegura a permanência interpelante do "nosso" mundo, sendo capaz de o fazer mesmo contra as limitações reconhecidas conscientemente no corpo considerado expressamente. O mesmo é dizer que o corpo habitual consegue segurar e recuperar o tempo que se julga perdido.

Esta dimensão ou possibilidade do corpo é resumida por Merleau-Ponty-Ponty na importante noção de "arco intencional" 58 , com a qual aborda o modo como o dinamismo corporal é implícita e constitutivamente espacial mas também temporal, orientando-se para o mundo como uma espécie de

D. Leder). Os perigos do dualismo que sempre ameaçam reentrar no debate (e dos quais a polaridade leib / körper precisa de se precaver), apenas assim podem ser afastados: a "consciência incarnada", relida como "consciência não-intencional do corpo intencional", (D. Legrad) demonstra a irredutibilidade do corpo a qualquer definição como mero objeto e, ao mesmo tempo, evita os escolhos de uma identificação do corpo com uma pura subjetividade. Em segundo lugar, enfim, é por ser assim ambíguo no seu fundo que o corpo poderá ser abordado "de dois lados", não apenas "por cada um de nós em relação com o seu 'si', mas também por cada um de nós em relação aos outros." (Sobchack). A este corpo que, desvendado no membro fantasma será também o corpo da dor do "outro", daremos atenção mais detalhada em trabalho que projetamos como continuação do que agora se publica.

56 Merleau-Ponty, Phénoménologie, 95.

57 Merleau-Ponty, Phénoménologie, 95.

58 Merleau-Ponty, Phénoménologie, 158. 
"diafragma interior" 59 que retém o passado e o projeta constantemente para o futuro. Numa passagem central da Phénoménologie, é nestes termos que tal conceito se esclarece:

A vida de consciência - vida que conhece, vida do desejo, ou vida percetiva - é sustentada por um 'arco intencional' que projeta em redor de nós o nosso passado, o nosso futuro, o nosso meio humano, a nossa situação ideológica, a nossa situação moral, ou melhor, que faz com que nós sejamos situados por todas essas relações ${ }^{60}$.

Será por força de tal arco que a "unidade dos sentidos, a unidade dos sentidos e da inteligência, a unidade da sensibilidade e da motricidade"61 serão mantidas e conservadas. $\mathrm{O}$ que não é dizer pouco, já que se deverá ainda acrescentar - aspeto decisivo para o que aqui nos interessa - que será esse mesmo arco intencional que "se "distende' na doença" 62 . Se acrescentarmos à afirmação anterior o caso da amputação e aplicarmos a uma fenomenologia do membro-fantasma o que tal noção de "arco intencional" pode albergar, compreendemos as implicações a sublinhar: tal distensão, de facto, explica como um membro que já não existe objetivamente pode continuar a ser experimentado no presente e a ser descrito de modo consideravelmente rigoroso nas suas particularidades. Se isto acontece é, primeiro que tudo, porque o amputado, "do mesmo modo que o sujeito normal, não precisa, para se pôr a caminho, de uma perceção clara e articulada do seu corpo: basta tê-lo 'à sua disposição' como uma potência indivisa e adivinhar a perna fantasma vagamente implicada nele"63; deve acrescentar-se que tal corpo anonimamente disponível parece ser capaz de persistentemente continuar operante como potência indivisa, mesmo quando o seu modo de aparecer silencioso é quebrado pela evidência traumática de uma ausência no corpo físico. Trata-se neste caso de um duplo desaparecimento (do silêncio do corpo vivido ${ }^{64}$ e de uma parte do corpo físico) que, inesperadamente, produz uma estranha positividade: a presença de uma ausência, ou seja, a experiência no presente de um membro que, digamos assim, já é passado. Independentemente da consciência expressa do sujeito amputado (que sabe o seu membro amputado já ausente e, eventualmente, tenta ultrapassar o trauma da amputação), a potência indivisa" que o corpo habitual não deixa de ser continua a projetar em

59 Merleau-Ponty, Phénoménologie, 95.

60 Merleau-Ponty, Phénoménologie, 158.

61 Merleau-Ponty, Phénoménologie, 158.

62 Merleau-Ponty, Phénoménologie, 158.

63 Merleau-Ponty, Phénoménologie, 96.

64 Da des-aparição do corpo, se quisermos utilizar a expressão de D. Leder em D. Leder, The Absent Body, (Chicago, University of Chicago Press, 1990), 90 ss. 
redor do amputado o meio humano que era o seu antes da amputação - como se tal meio humano permanecesse presente e o corpo recusasse a impossibilidade de lhe corresponder, antes continuando a manter aqui e agora uma justa resposta prática.

"Ter um braço fantasma - escreve Merleau-Ponty - é permanecer aberto a todas as ações das quais apenas o braço é capaz, é conservar o campo prático que se tinha antes da mutilação" 65 . Neste gesto, de algum modo, o corpo habitual "recusa" a amputação ao não deixar que o membro amputado passe definitivamente para o passado. Neste sentido, a presença do membro ausente não será uma "representação", mas, como nota Merleau-Ponty, uma "presença ambivalente" 66 , uma "quase presença" sentida agora e não num passado que se re-apresentaria. Trata-se, efetivamente, de uma situação equívoca: o amputado sabe que não tem a perna amputada e, no entanto, continua a contar com ela quer queira quer não, já que o corpo habitual continua a ser a mesma vocação desse mesmo mundo ${ }^{67}$ que exigia do corpo completo, antes da amputação, determinados gestos, tarefas ou comportamentos. Neste sentido, pode dizer-se que o corpo habitual continua a negociar a sua própria forma e os seus próprios limites com o espaço e os objetos que são os seus "polos de ação", assim confirmando que o tempo é conservado originariamente por força de uma espacialidade de situação negociada corporeamente. De facto, a fantasmagoria do membro amputado surpreende no momento em que a interpelação prática do mundo, ao mesmo tempo que mascara a amputação (porque continua a oferecer ao corpo anónimo os mesmos polos de ação aos quais, enquanto unidade vivida, tal corpo co-responde sempre pré-pessoalmente), a revela ${ }^{68}$, ao continuar a "exigir" as tarefas e comportamentos de um membro que, objetivamente, já não existe (num corpo que não deixa de ser o mesmo pivot do mundo). Tudo se passa, portanto, como se um mundo familiar continuasse a "suscitar em mim intenções habituais" a que já não posso co-responder "se sou amputado", mas às quais continuo aberto com a conivência anónima de um corpo que, por debaixo do corpo atual, se recusa a ficar preso à amputação.

Para ilustrar o que aqui está em questão, Merleau-Ponty alinha, na Phénoménologie, o caso do membro-fantasma com a situação de luto e, numa passagem onde a beleza da expressão se alia ao rigor da exemplificação, escreve:

65 Merleau-Ponty, Phénoménologie, 97.

66 Merleau-Ponty, Phénoménologie, 96.

67 Merleau-Ponty, Phénoménologie, 95. É assim que, por exemplo, “certos pacientes podem estar próximos da cegueira sem terem mudado de mundo".

68 Merleau-Ponty, Phénoménologie, 97. 
Enquanto estou abatido por um luto e a sofrer, os meus olhares erram já diante de mim, interessam-se sorrateiramente por um qualquer objeto brilhante, recomeçam a sua existência autónoma ${ }^{69}$.

Também o fenómeno do membro-fantasma se enraizará no desajustamento perturbador entre o que sei já "defunto" (o membro objetivamente amputado e o mundo que lhe correspondia) e o que o corpo habitual "obriga" a viver como presente (um membro já "morto" que se recusa a passar para o passado, um membro que perdura como a presença de uma ausência), por continuar a "interessar-se sorrateiramente" pelo mundo que o envolve e situa. É este o fundo da tensão a que aludimos atrás entre o que se conhece no corpo por reflexão expressa e o que o corpo "conhece" por sedimentação prática. No caso da experiência do membro-fantasma tal tensão é, na verdade, nuclear: frente aos objetos do mundo ainda manejáveis, as convicções e evidências reflexivas sobre a ausência da parte do corpo que poderia responder ao apelo prático do manejável não são suficientes para impedir que o corpo habitual continue a ser o fiador do corpo atual e a manter intacta a ponte com o campo prático. Dito de outro modo, no caso do membro-fantasma tudo se joga na polémica entre as limitações percebidas no corpo atual (que, desde a "fase do espelho"70, aprendemos a nomear ao ligar as palavras, o que vemos e o que tocamos a uma espacialização circunscrita e segmentada do corpo) e a vocação do seu fiador, o corpo habitual, para manter fantasmagoricamente presente - e como algo do presente - o que objetivamente já morreu.

Se o corpo habitual assim "recusa" a amputação não é, no entanto, no mesmo sentido em que mais ou menos expressamente se pode "entrar em negação" face ao "novo" corpo objetivamente diminuído; aquela primeira "recusa" é outro modo de dizer que o corpo habitual nunca se detém num qualquer estado definitivo, nunca se fixa, nunca se fecha, mas em cada momento visa já sempre um novo desafio prático; é por propagação transparente, alienação dinâmica, pertença silenciosa e conivência sorrateira - que podemos entender como outras tantas modalidades anónimas de uma visão pré-objetiva - que o corpo habitual segura, contra todas as expectativas da consciência expressa, o mundo passado e já morto, mantendo-o presente sem qualquer referência ao passado num fantasma disponível para novas efetuações. No silêncio ou sombra da amputação, o corpo habitual agarra-se (e agarra-nos) a um tempo estabelecido no passado, mas projetado no futuro

69 Merleau-Ponty, Phénoménologie, 100

70 Cf. Henri Wallon, Les origines du caractère chez l'enfant. Les préludes du sentiment de personnalité, (Paris : PUF, coll. «Quadrige Le psychologue », 1983). Jacques Lacan, Le Stade du miroir comme formateur de la fonction du Je : telle qu'elle nous est révélée dans l'expérience psychanalytique (Paris : P.U.F., 1949). 
de ações possíveis; e as reencenações práticas de que é capaz, a persistência dinâmica com que guarda o manejável dos objetos do mundo tal como "falavam" ao corpo antes da amputação são o emblema de tal tempo recuperável.

Perceber-se-á agora um pouco melhor em que sentido a experiência do membro-fantasma se torna ambivalente ${ }^{71}$ : por um lado, o amputado sabe expressamente que o seu corpo perdeu uma parte; por outro, na surpresa de um membro fantasma que chega a ser capaz de descrever minuciosamente como real, faz a experiência de uma continuidade de si próprio, de uma integridade de si que não parece depender de si. Tudo se passa, portanto, como se a profundidade temporal da experiência pessoal nos chegasse do dinamismo anónimo e pré-pessoal de incorporação, anexação, virtualização e sedimentação do corpo habitual. E como os "produtos" de tal dinamismo são independentes do que possamos querer ou pensar, serão sempre vividos como bizarra "assombração" 72 de tudo o que, do mundo, faz falta no corpo e de tudo o que, no corpo, persistentemente continua a ser do mundo. Sob a amputação, o corpo permanecerá, portanto, uma espécie de "agenciamento espectral"73 sempre a esboçar um meio termo entre presença e ausência. O que não será dizer pouco: mais do que atribuir ao corpo um lugar central no contexto da experiência do mundo, Merleau-Ponty desvenda nos agenciamentos espetrais do corpo habitual, enquanto estes se enraízam na respetiva capacidade para guardar e reencenar sedimentações práticas, algo de fundamental para a própria noção de permanência de um "Eu consciente": de facto, parece ser a memória prática do mundo, guardada e reencenada pela motricidade do corpo habitual, que dá espessura temporal ao modo incarnado de ser no mundo. Dito de outro modo: o "Eu" consciente "seria fragmentado se a memória fosse apenas uma questão cognitiva" 74 e não, precisamente, questão do próprio modo de pertença persistente e duradoura ao mundo esboçada, pré-pessoalmente, pelo corpo habitual. Um sentido básico de continuidade do "Eu" na experiência traumática da amputação depende, pois, desta capacidade do corpo anónimo para assim impedir ou recalcar a passagem definitiva de "um antigo presente" para o passado ${ }^{75}$ : tal continuidade é assinalada, precisamente, pela tensão ou fratura temporal que, no centro de tal experiên-

71 Merleau-Ponty, Phénoménologie, 96.

72 Merleau-Ponty, Phénoménologie, 159-161: «Dans le geste de la main qui se lève vers un objet est enfermée une référence à l'objet non pas comme objet représenté, mais comme cette chose très déterminée vers laquelle nous nous nous projetons, auprès de laquelle nous sommes par anticipation, que nous hantons.»

73 Trigg, The Memory of Place. A Phenomenology of the Uncanny, (Ohio: Ohio University Press, 2012), 16.

74 Trigg, The Memory of Place, 17.

75 Merleau-Ponty, Phénoménologie, 101. 
cia, se torna evidente entre o sentido de continuidade sedimentado no corpo habitual e a perda objetiva do mundo ao qual respondia o membro amputado.

\section{Membro-fantasma, memória-fantasma.}

A ser correto o que fica dito, torna-se claro que a abordagem merleu-pontyana do membro-fantasma nos leva a ultrapassar tanto a consideração simples da mutilação do corpo físico, como as aproximações "psíquicas"; na verdade, trata-se de colocar a questão do lado de uma improvável experiencia temporal estruturada pelo arco intencional, experiência essa que conta a história de uma recusa ou "recalcamento" "76 do que ameaça a vocação de unidade vivida própria do ser-no-mundo. O que em nós recusa a mutilação é um eu comprometido com um certo mundo físico e inter-humano; mas, justamente, tal repressão do tempo, tal recusa em deixar o passado ser esquecido, depende originariamente das sedimentações práticas e do agenciamento espetral do corpo anónimo. É assim que se dá a situação de, ao mesmo tempo, não se querer enfrentar a nova circunstância traumática de se ser amputado e, todavia, não a poder abandonar por força da persistência do corpo habitual. Acontece aqui um conflito entre o tempo pessoal, que é bloqueado (já que a amputação leva a reconhecer expressamente o que já não é possível fazer com o corpo físico), e o tempo impessoal e duradouro enraizado no agenciamento espectral (estruturalmente rememorador) do corpo dinamicamente comprometido com o seu campo prático. E tal conflito é tanto mais poderoso quanto o poder do corpo anónimo é capaz de contradizer a evidência reflexiva. Dito de outro modo, tal corpo - que não deixamos de ser - tem suficiente força para continuar a operar autonomamente. Este ponto é importante: não haveria experiência do membro-fantasma se o corpo habitual, pré-pessoal, corpo que se apaga para que eu tenha mundo, não se desvendasse na amputação através de uma estranha e perturbadora autonomia que aparece ao reprimir a amputação. Numa palavra, como nota Merleau-Ponty, "o fenómeno do membro-fantasma junta-se ao do recalcamento que o vai esclarecer" 77 .

Não se trata, no entanto, de supor, neste contexto, um inconsciente entendido psicanaliticamente com os seus mecanismos de censura e repressão; outrossim, trata-se de nomear uma alteração do estar no mundo que passa pela "queda" do poder da existência na "primeira pessoa", pela revelação da impotência do $E u$ consciente, cujo tempo se descobre, subitamente, mantido

76 Merleau-Ponty, Phénoménologie, 98 : «Corrélativement, il faut que mon corps soit saisi non seulement dans une expérience instantanée, singulière, pleine, mais encore sous un aspect de généralité et comme un être impersonnel.»

77 Merleau-Ponty, Phénoménologie, 98. 
por um corpo anónimo que continua a desejar a sua própria unidade como contrapartida da unidade do mundo. Dito de modo mais preciso,

todo o recalcamento é então uma passagem da existência na primeira pessoa a uma espécie de escolástica dessa existência, que vive sobre uma experiência antiga ou antes sobre a recordação de a ter tido, depois sobre a recordação de ter tido essa recordação, e assim por diante, ao ponto de finalmente ela não reter senão a sua forma típica. ${ }^{78}$

O recalcamento da passagem do passado para o esquecimento é, neste sentido, garantido pela intencionalidade motora do corpo habitual, que se tece de uma efetiva combinação entre orientação significativa para uma situação prática e reencenação não representativa de um passado prático sedimentado nos "arquivos indestrutíveis" da motricidade. Tal articulação entre memória e reencenação corporalizada é, pois, o fundo da própria vocação de unidade do mundo que o corpo - sob um aspeto de generalidade e como ser impessoal" $l^{79}$ - não deixa de desejar, ao "emprestar-se sem reserva à ação". Neste gesto, enfim, mantém presente o que a consciência expressa já só pode conceber como ausência, ruina ou morte de um certo mundo e de um certo corpo.

Não somos, nesta circunstância, muito diferentes do inseto que, mesmo perdendo uma pata, "simplesmente continua a pertencer ao mesmo mundo e nele se move com os seus poderes" 80 : sob o corpo atual amputado, o corpo habitual continua a co-responder ao mundo como se este mantivesse todo o seu significado; fá-lo através de um trabalho minucioso e anónimo de reajustamento dos reflexos (nunca cegos) de sincronização (nunca perfeita e sempre em afastamento, em écart) com o mundo, assim mantendo o campo prático presente com uma força tal que nenhum inquérito intelectual consegue anular. A delonga do corpo pré-mutilado implica, portanto, um efeito bizarro de transformação temporal do espaço, por força da qual coisas do passado aparecem subitamente na escala espácio-temporal do presente da amputação e a esburacam: um membro do corpo e um campo prático deixam ambos de ser "do passado" e chegam ao presente. Este aspeto do problema parece-nos decisivo: o tempo passado "não se fecha sobre a experiência traumática" porque o sujeito continua forçosamente aberto a um mesmo "futuro impossível", não por força dos seus pensamentos expressos, mas do seu ser efetivo (e do seu corpo habitual).

O membro amputado continua a contar no "grande esquema das coisas" do sujeito amputado, ao mesmo tempo que introduz no centro da experiên-

78 Merleau-Ponty, Phénoménologie, 99.

79 Recorde-se Merleau-Ponty, Phénoménologie, 98.

80 Merleau-Ponty, Phénoménologie, 92. 
cia uma vivência equívoca do tempo do "Eu": o sentido de continuidade do tempo pessoal não é bloqueado pelo momento traumático e um tempo impessoal continua a escoar-se ${ }^{81}$ e a projetar-se sobre o futuro de uma renovada anexação do campo prático. Ao diferir o "luto" do membro amputado, o corpo habitual mantém presente em redor do sujeito consciente o que este sabe expressamente ser "passado" (o momento do trauma), o que este tenta "deixar" no passado, o que sabe expressamente ter desaparecido (o membro amputado) e quer "esquecer"; traz-lhe, pois, um fantasma, ou seja, a estranheza de uma presença que assombra sob a forma de uma ausência incontrolável quem vem, de algum modo, do "mundo dos mortos". Eis o sentido derradeiro do "agenciamento espetral" do corpo: enquanto complexo inato ${ }^{82}$, o corpo opera por debaixo da existência pessoal para sobre ela projetar o sentimento angustiante de um fundo inumano e tacitamente presente, de um fundo que permanece "atrás do nosso olhar em lugar de se dispor frente a ele"83 e é a própria estrutura temporal arcaica do ser-no-mundo. O poder de recalcamento do corpo anónimo partilha, portanto, de algum modo, um "fenómeno universal" 84 de recalcamento, cujo traço característico é o de contribuir para manter em "redor da nossa existência pessoal uma margem de existência quase impessoal (...), um mundo em geral" 85 , um campo prático antigo e um corpo já desaparecido sem qualquer indicação de passado.

Assim sendo, dir-se-ia que o fenómeno do membro-fantasma se alinha com a experiência vivida de uma "memória-fantasma" que guarda todo o passado do próprio gesto de anexação corporal do mundo ${ }^{86}$. Tal memória seria já dispensável dizê-lo - não é a recordação expressa e pessoal de um passado "momentâneo" 87 , não é questão de uma "cogitatio exigindo uma outra cogitatio" 88 ; trata-se antes da preservação, no presente, de correspondências práticas significativas que, objetivamente (é este o caso do amputado, como também o das incorporações protésicas), já não existem - sedimentações de um passado que se continua a viver como o nosso verdadeiro presente. É esta a razão, acrescente-se, pela qual o recalcamento não dispersa ou aniquila o membro-fantasma, mas o situa como uma quase presença. De algum modo,

81 Merleau-Ponty, Phénoménologie, 100.

82 Merleau-Ponty, Phénoménologie, 99.

83 Merleau-Ponty, Phénoménologie, 99.

84 Merleau-Ponty, Phénoménologie, 99.

85 Merleau-Ponty, Phénoménologie, 98.

86 No duplo sentido do genitivo: gesto corporal sobre o mundo, gesto que é do corpo apenas porque igualmente do mundo

87 O que não significa que não se possa evocar a memória do membro antes da amputação, ou que algumas palavras sobre uma história análoga não possam motivar a recordação expressa, por exemplo, de momentos anteriores à amputação.

88 Merleau-Ponty, Phénoménologie, 102 
é o mesmo braço amputado, agora porventura já incinerado com o restante lixo hospitalar, que vem assombrar o corpo atual, sem na verdade se confundir com tal corpo que expressamente já não tem a "parte" amputada. Dito de outro modo, o membro-fantasma é "um antigo presente que não se decide a tornar-se passado" 89 , um antigo presente que já deveria estar morto e, no entanto, se mantém presente aqui e agora sem qualquer referência de passado - e se mantém com os seus contornos mais ou menos espalhados, com o seu tamanho mais ou menos telescopicamente móvel ${ }^{90}$, com as suas sensações mais ou menos situadas e com a suas dores mais ou menos (i)localizáveis. Todos temos os nossos fantasmas; os do amputado - membro-fantasma, dor-fantasma, memória-fantasma - vêm de facto do mundo dos mortos.

\section{6 - Equívocos e possibilidades (nota final).}

A ser verdade o que fica dito, uma fenomenologia do membro-fantasma denunciará um duplo equívoco funesto: o equívoco de se aceitar que existe uma diferença de natureza entre "fantasma" e "real" (com toda a evidência uma distinção sem sentido, já que a experiência do membro-fantasma e da dor fantasma são, de facto, reais); e o equívoco de se aprovar a prevalência que, nessa aporia, sempre ganha o "real" sobre o "fantasma" (opção ingénua e superficial, desenhada sobre critérios naturalistas).

Aqui chegados não estará, certamente, ainda tudo dito. Entre a liberdade selvagem e a servidão angustiante impostas pelo corpo habitual pressente-se o fundo inumano de toda a humanidade pessoal. O fantasma do membro ausente é tanto a presença, no presente, do tempo perdido, como a presença imemorial no corpo de uma continuidade espacial e temporal sem quebras para a qual a dimensão interpelante e incorporável do mundo não deixa de contribuir. Se quiséssemos utilizar os conceitos tardios de Merleau-Ponty, poderíamos dizer, finalmente, que o caso específico do membro-fantasma reclama que se considere, para lá do orgânico e para aquém do psíquico, em que medida os fantasmas que se vêm inscrever na carne do corpo são anúncio da carne do mundo ${ }^{91}$. Mas este é já certamente um novo trabalho.

89 Merleau-Ponty, Phénoménologie, 101.

90 Sobchack, "Living a Phantom Limb", 62: "Rather its lengthening (not longing) is a mobilization of my motor capacities to fulfil a present intention".

91 Maurice Merleau-Ponty, Le visible et l'invisible, (Paris: Gallimard, 1964). 


\section{Referências bibliográficas:}

Crawford, C.S., "From Pleasure to Pain: the role of the MPQ in language of phantom limb pain", in Social Science \& Medicine, 69(5), 2009, 655-661.

Crawford, C.S., "You don't need a body to feel a body: phantom limb syndrome and corporeal transgression", in Sociology of Health \& Illness, 35 (3), 2013, 1-15.

Gallagher, Shaun, "Body schema and intentionality", in J. L. Bermudez, A. Marcel and N. Eilan (eds.), The Body and the Self, Cambridge, The MIT Press, 1995, $225-244$.

Haro, Agustín Serrano de, "Atención y dolor. Análisis fenomenológico", in AAVV, Cuerpo Vivido, Madrid, Encuentro, 2010, 123-161.

Jackson, J. Hughlings, Selected writings, London, Hodder and Stoughton, 1932.

Lacan, Jacques Le Stade du miroir comme formateur de la fonction du Je: telle qu'elle nous est révélée dans l'expérience psychanalytique, Paris, P.U.F., 1949

Leder, Drew The Absent Body, Chicago, University of Chicago Press, 1990.

Legrand, Dorothée "The bodily self: The sensori-motor roots of pre-reflective self-consciousness", in Phenomenology and the Cognitive Sciences, $\mathrm{n}^{\circ} 5$ (2006), 89 $-118$.

Melville, Herman, Moby Dick, (trad. Port.), Lisboa, Relógio d'Água, 2005.

Melzack, R. "Phantom limbs" in Scientific American, no 266 (1992), 120-126.

Melzack R. "From the gate to neuromatrix", in Pain 1999; Suppl. 6:S 121-6.

Merleau-Ponty, Maurice, Phénoménologie de la perception, Paris, Gallimard, 1945.

Merleau-Ponty, Maurice, Psychologie et pédagogie de l'enfant. Cours de Sorbonne 1949-1952, Paris, Verdier, 2001.

Merleau-Ponty, Maurice, La Nature. Notes de cours du Collège de France, Paris, Seuil, 1994.

Merleau-Ponty, Maurice, Le visible et l'invisible, Paris, Gallimard, 1964.

Mitchell, S. W. «Phantom limbs», in Lippincott's Magazine of Popular Literature and Science, vol. 8 (1871), 563-569.

Nortvedt, Finn, Engelsrud, Gunn "Imprisoned in pain: analysing personal experiences of phantom pain", in Medical Health Care and Philosophy, n 17 (2014), pp. 599-608.

Paré, Ambroise, Oeuvres complètes d'Ambroise Paré (t. I, II, III) avec les variantes [...], accompagnées de notes historiques et critiques et précédées d'une introduction sur l'origine et les progrès de la chirurgie en Occident du sixième au seizième siècle et sur la vie et les ouvrages d'Ambroise Paré par J.-F. Malgaigne, Paris, London, 1840-1841. Acesso em http:/gallica.bnf.fr/ark:/12148/ bpt6k65305763/f44.item.r=sentir,\%20membre.

Ramachandram, V. S., Hirstein, W. "The Perception of Phantom Limbs. The D. O. Helb Lecture", in Brain, no 121 (1998), pp. 1603- 1630.

Saint Aubert, Emmanuel "Espace et schéma corporel dans la philosophie de la chair de Merleau-Ponty", in A. Berthoz, B. Andrieu (dir.) Le corps en acte, Presse Universitaire de Nancy, 2010, 122-152.

Sobchack, Vivian "Living a Phantom Limb: on the Phenomenology of Bodily Integrity", in Body and Society, vol. 16, nº 3 (2010), 51-67. 
Toombs, S. Kay, The Meaning of Illness. A Phenomenological Account of the Different Perspectives of Physician and Patient, Springer Science, Business Media, B.V., 1992,

Trigg, Dylan, The Memory of Place. Phenomenology of the Uncanny, Ohio, Ohio University Press, 2012.

Trigg, Dylan, The Thing. A Phenomenology of Horror, Zero Books, 2016.

Wallon, Henri, Les origines du caractère chez l'enfant. Les préludes du sentiment de personnalité, Paris, PUF, coll. « Quadrige Le psychologue », 1983.

Woodhouse, Annie, "Phantom Limb Sensation", in Classical and Experimental Pharmacology and physiology, 32 (2005), 132-134. 